\title{
La Opinión pública. Un operador polivalente
}

\author{
The public opinion: a polyvalent operator
}

\author{
Teresita Vásquez Ramírez ${ }^{1}$ \\ Vásquez R, Teresita \\ miradas $\mathrm{N}^{\circ} 14$ - 2016. ISSN: 0122 994X Págs 71 - 80 \\ Recepción: Junio 18 de 2016 \\ Aprobación: Octubre 03 de 2016 \\ Publicación: Diciembre 20 de 2016
}

\begin{abstract}
"Si una cosa puede existir en la opinión sin existir en la realidad, y existir en realidad sin existir en la opinión, hay que concluir que de ambas existencias paralelas la única necesaria es la de la opinión, y no la de la realidad"
\end{abstract}

Joaquim María Machado de Assis. La théorie du médaillon et autres contes.

\section{Resumen:}

Al hacer un breve rastreo del significado que se le ha conferido a la noción de opinión pública a partir de diferentes fuentes: lexicográficas, eruditas y doxásticas se puede constatar el manejo ambiguo que se ha hecho del sintagma y que no existe una definición plausible y de aceptación general para la comunidad académica. ¿Cómo analizar, entonces, el modo de existencia de la opinión? Reconocer la existencia semiolingüística de la opinión pública nos sitúa en el campo de los estudios discursivos, y abre varios caminos de reflexión que sirven a nuestro propósito: ¿Quién hace existir la opinión pública en el discurso y a quién está destinada? ¿Qué estrategias discursivas permiten presentarla como actante? ¿Cómo se fabrica el simulacro de opinión pública?

Palabras claves: Opinión, portavoces, coro, corifeo

1 Docente Universidad Tecnológica de Pereira. Magíster en Comunicación Educativa. Candidata a Doctora en Humanidades. Cohorte: Análisis del discurso.tevara@utp.edu.co 


\section{Abstract:}

Given a brief investigation of the meaning conferred upon the notion of public opinion from different sources-lexicographic, erudite, and doxastic - the ambiguity of understanding around this notion's syntagma is clear and there is no acceptance within the academic community of any plausible definition. How then can we analyze the mechanism from which opinion emanates? Recognizing the semiolinguistic existence of public opinion places us in the field of discursive studies and opens up several questions for reflection that serve our purpose: Who makes public opinion exist in discourse and to whom is it intended? What discursive strategies can you present as actants? How is the simulacrum of public opinion produced?

Key Words: opinion, spokesman, chorus, coryphaeus

Al hacer un breve rastreo del significado que se le ha conferido a la noción de opinión pública, a partir de diferentes fuentes: lexicográficas, eruditas y doxásticas se puede constatar el manejo indeterminado que se ha hecho del sintagma y que, por lo tanto, no existe una definición plausible y de aceptación general para la comunidad académica.

En cuanto al tratamiento lexicográfico, los diccionarios de la Real Academia (DRAE), el Larousse y María Moliner nos aportan la siguiente acepción: la opinión pública es el «sentir o estimación en que coincide la generalidad de las personas acerca de asuntos determinados». El semema, en cuestión, nos plantea que la opinión es un juicio o valoración respecto de un tema determinado que tiene la característica de ser compartido por un número mayoritario de personas, dicho de este modo, la opinión pública ha de entenderse como aquello que siente y estima la gente, creencias, tradiciones y prejuicios que se expresan como una voluntad común.
Respecto a las fuentes eruditas, en la tesis doctoral 1 "Comunicación electoral y formación de la opinión pública", López, García (2001) realiza un minucioso estado de la cuestión del que hemos seleccionado algunas definiciones que han marcado tendencia en los estudios sobre la opinión pública.

Elisabeth Noelle-Neumann (1974) desde su teoría de la espiral del silencio construye una definición operativa en la que plantea que «los temas controvertidos se expresan en público y el clima de opinión depende de quien hable y quien permanezca en silencio». Para Jürgen Habermas (1962) «la opinión pública adopta una actitud crítica frente al poder político, en tanto en cuanto está compuesta por individuos racionales. La opinión pública, para Habermas, surge en el ámbito de la publicidad burguesa, pero acaba por afectar al conjunto de los ciudadanos, cuanto menos a los ciudadanos ilustrados». Giovanni Sartori (1987) sostiene que la opinión pública es ante todo y sobre todo un concepto político. Para el investigador italiano la opinión pública es "un público, o multiplicidad de públicos, cuyos difusos estados mentales (de opinión) se interrelacionan con corrientes de información referentes al estado de la res pública. Kimball Young (1995) destaca que «Una importante tesis sobre la opinión pública deriva de la creencia en que el hombre es racional y objetivo. Esta escuela dice que la opinión pública es un juicio de grupo más o menos racional, y por lo tanto, debe ser cuidadosamente distinguida de las emociones y sentimientos públicos. Supone además que tal juicio racional surge de una consideración fría y desinteresada del asunto». Cándido Monzón (1996) nos dirá que la opinión pública es «la suma de las opiniones y actitudes individuales, perspectiva que entronca con el conjunto de creencias predominantes en una determinada comunidad». Irving Crespi, (2007) por su parte, afirma que la opinión pública «se forma a partir de opiniones 
individuales, éstas desde el principio están mediadas por una serie de factores de índole social de tal forma que, por decirlo así, la opinión pública acaba siendo un proceso colectivo con identidad propia, creado a partir de la interactuación de una serie de actores individuales que se influyen mutuamente a lo largo de un proceso determinado». Por su parte, Bourdieu (1979) sostiene que la opinión pública no existe, planteamiento que sustenta sobre tres hipótesis : (1) suponer que todo el mundo tiene una opinión, (2) suponer que todas las opiniones valen, (3) hacer la misma pregunta a todo el mundo, implicando que hay un consenso sobre los problemas. No se trata de negar que la gente pueda emitir opiniones sobre un asunto de interés general, sino de comprender que las opiniones están sujetas a variables muy diversas, clase social, grado instruccional, postura ideológica, edad, género y que incluso en algunos casos se puede no tener una opinión frente a un tema en cuestión; por otro lado, que las opiniones tal como las registran los sondeos son siempre el resultado de un compendio de opiniones individuales que hacen sumatoria y no el efecto de una discusión como habitualmente sucede entre los ciudadanos.

Las problemáticas que son propuestas por los sondeos de opinión son subordinadas a intereses políticos, y esto dirige, muy fuertemente a la vez, el significado de las respuestas y el significado que se consagra a la publicación de los resultados. El sondeo de opinión es, en el estado actual, un instrumento de acción política; su función más importante consiste posiblemente en imponer la ilusión de que existe una opinión pública como sumatoria puramente aditiva de opiniones individuales; al imponer la idea de que existe algo que figura como la media de las opiniones o la opinión media.

Estas conceptualizaciones que provienen de diferentes campos disciplinares, al igual que las definiciones lexicográficas aportadas por los diccionarios, sugieren dos observaciones, la primera, que todas ellas coinciden en conferir a la opinión pública una existencia empírica, en tanto que ésta es atribuible a los individuos de una sociedad, la opinión pública está «compuesta por individuos racionales, por un público o multitud de públicos, es un juicio de grupo», etc.; la segunda observación tiene que ver con que la opinión pública es, en suma, el conjunto de creencias y sentires de esos grupos o individuos, ya sea que se trate de una opinión crítica e ilustrada o que se refiera a un llano sentido común. (Bourdieu. 1972 p. 17)

Para Bourdieu, la opinión pública no es más que un artefacto construido por la clase dirigente en favor de sus intereses y cálculos políticos, un dispositivo de poder que configura de manera ilusoria una comunidad de diálogo, de encuentro y acuerdo en torno al asunto tratado. En este sentido, construir opinión pública para quienes detentan el poder sobre los medios, significa, entonces, dar existencia a través del discurso lo que se pretende, sea legitimado, es crear una ilusión referencial y asignársela a la ciudadanía para que esta se sienta protagonista de las decisiones.

\section{Una perspectiva semiótica:}

De acuerdo con Landowski (1989), tanto las empresas encuestadoras, como los medios de información y los políticos se ocupan, cada uno a su manera, del fenómeno de la opinión pública. Mientras las primeras recurren a técnicas de muestreo y "actividades objetivantes", los segundos se presentan como una especie de oráculo o portavoces capaces de dar cuenta de los estados del alma de un personaje llamado Opinión. A pesar de que ambas "escuelas" mantienen relaciones estrechas y en algunas ocasiones pueden llegar a tener un marcado tinte clientelista, mutuamente se cuestionan. Para los portavoces, los sondeos solo tienen un valor aproximativo 
y, cuando más, podrían dar cuenta de un estado de la opinión en un momento determinado; los encuestadores, por su parte, se preguntan que quieren designar los portavoces y políticos cuando emplean la palabra opinión y con qué método determinan sus preocupaciones" (p. 22-23)

Dice Landowski:

La cuestión así planteada puede interpretarse de dos maneras diferentes, según se considere, por un lado, como un problema relativo a la realidad empírica de la "cosa" designada $-\mathrm{y}$ en este caso es muy probable que la expresión "opinión pública", en su uso corriente, no designe "nada" porque efectivamente no tiene referente estrictamente asignable-, o si se refiere a las condiciones de empleo de la "palabra" misma y a la aprehensión de su significación, caso en el cual es necesario admitir la evidencia de que, en tanto que realidad semiolingüística, "la opinión pública existe", ya que incluso desprovista de referente, la expresión no está desprovista de sentido. (Landowski: 1989 p. 23)

Esta oposición entre la realidad empírica y realidad semiolingüística, pone de manifiesto que la opinión pública no existe ni antes ni más allá del discurso, lo que lleva a Landowski a formular la pregunta ¿Cómo analizar el modo de existencia semiótica de la opinión? Así, pues, reconocer la existencia semiolingüística de la opinión pública, nos sitúa en el campo de los estudios discursivos, y abre varios caminos de reflexión que sirven a nuestro propósito: ¿Quién hace existir la opinión pública en el discurso y a quién está destinada? ¿Qué estrategias discursivas permiten presentarla como actante? ¿Cómo se fabrica el simulacro de opinión pública?

\section{Modos de existencia semiótica de la opinión:}

Para analizar las operaciones mismas que esta noción hace posible, [Landowski propone] pasar de la descripción del sistema actancial subyacente al estudio de su realización bajo la forma de procesos semiolingüísticos particulares. Inscritos en el discurso de los periodistas y de los políticos, esos procesos pueden ser analizados en dos niveles, tomando en cuenta la distinción elemental entre el plano del enunciado y el de la enunciación:

En el plano enuncivo: la opinión es construida como un actor discursivo que desempeña un papel en el relato: protagonista «encargada de motivar la acción de los gobernantes con la ayuda de otros actantes narrativos» o portavoces (Landowski. 1989 p. 33). Este sujeto actorializado y figurativizado generalmente bajo la representación de lexemas como «los colombianos« o «los ciudadanos» es dotado de una voz propia, a través de la cual demanda, increpa o apoya a la clase dirigente para hacerla actuar.

Cuando se construye discursivamente en el plano enunciativo, «La opinión se transforma entonces en un operador discursivo al servicio de ciertas estrategias de persuasión e intervendrá en estos casos como un simulacro de los "gobernados" construido para hacerles asumir ciertas convicciones y, así, modelar sus comportamientos» (Landowski. 1989 p.33). Configurada como destinatario del enunciado, cuya función es la de interpretar, el actor opinión es situado en posición de observador, sujeto cognitivo que construye sus propios juicios epistémicos.

La siguiente gráfica muestra el ejemplo de la opinión en el plano enunciativo y enuncivo: 


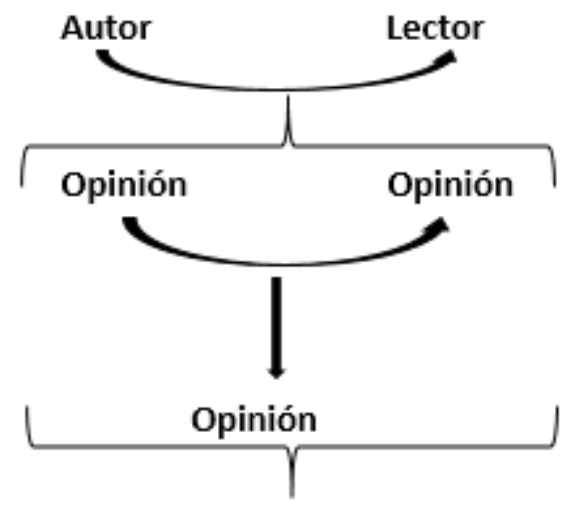

Figura 1. La opinión en el plano enunciativo y enuncivo.

\section{Una analogía: del teatro griego al teatro de la vida política}

Apoyado en la cultura teatral de la antigua Grecia, Landowski, establece una comparación entre los elementos que componen la dramaturgia de los clásicos y la dramaturgia política de la contemporaneidad.

\section{Así lo ilustra el autor:}

[...] Así como en Atenas la organización espacial del teatro reposaba sobre la distinción entre la escena propiamente dicha - logeiony la orquesta, desde donde el coro observaba las peripecias de la acción y las comentaba para los espectadores, encaramados en las gradas del Koilon, también la organización ideológica que sostiene hoy el espectáculo de la vida política a través de los "medios" tiene como principio el establecimiento de una disyunción neta (en términos figurativos, de un "foso") entre una clase de sujetos actuantes - los "héroes", la "case política", donde se codean gobernantes y estados mayores de los partidos, dirigentes sindicales y representantes del gran patronato o de la alta administración, etc. - y la "Opinión", instancia testigo que asiste al "espectáculo" e interpreta su significación, ya sea por cuenta propia o, por lo general, dirigiéndose a un público situado en un tercer plano. [...] en la medida en que esa actividad interpretativa, a través de la cual se expresan las reacciones y-¿por qué no?las opiniones de la opinión, toma específicamente por objeto los actos y las situaciones que hacen la trama de la "vida política, se puede decir que la Opinión se revela aquí politóloga a su manera (Landowski. 1989 p. 26)

Representación gráfica del teatro griego, los actores y sus correspondientes en el teatro de la vida política:

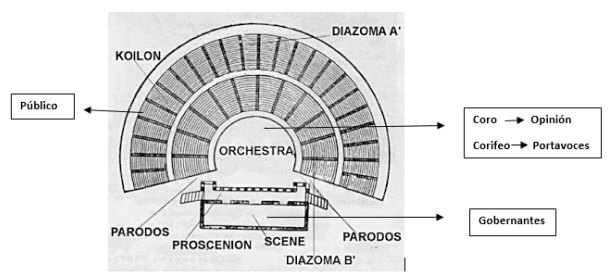

Figura 2. El teatro griego y la Opinión http://www.guiadegrecia.com/general/ teatro.html

Tal como lo explica Landowski, el logeion, era el lugar de la escena, ubicada detrás de la orquesta y elevada tres metros por encima de la misma, donde los actores realizaban la representación; en el centro, en un espacio que mediaba entre la escena 
y el público se situaba la orchestra y en ella el coro y el corifeo, constituidos por dos grupos de cantores: el coro, personaje colectivo, que comentaba y juzgaba lo que ocurría, representaba al ciudadano con el cual todos tenían algo en común, a través de él se comentaban los episodios de la trama para ayudarle al público a interpretar. En su función de analista, describía lo que pensaban los personajes y se dejaba guiar por el corifeo, este último, como observador, asumía la representación de otras personas, se expresaba por ellas, dirigía al coro y hablaba en nombre de él; el Koilon o graderío, que significa: lugar desde donde se contempla, era un espacio de forma semicircular reservado para el público.

\section{Público, espectadores, gobernados: la instancia ciudadana}

Tradicionalmente se piensa que frente a los gobernantes, instancia política que tiene el poder de hacer y el poder de decidir frente a la administración del bien común, se encuentran los gobernados, instancia ciudadana que ocupa el lugar donde se construye la opinión pública por fuera de los gobernantes.

\section{A este respecto dice Landowski:}

\section{[...] A primera vista no se} superponen tres actantes [tal como lo muestra la analogía del teatro griego] sino solamente dos porque se dirá que Frente a la clase política no hay el equivalente de un coro (que sería la opinión en tanto instancia autónoma) ni el equivalente de los espectadores (concebidos como un público distinto de la instancia opinante) sino un solo actor: la sociedad civil o los gobernados, un público que opina que dice el mismo sus propios sentimientos.

(Landowski. 1989 p. 27)

$\begin{array}{cc}\begin{array}{c}\text { Lugar de las } \\ \text { instancia ciudadana } \\ \text { o gobernados en la } \\ \text { perspectiva sociológica } \\ \text { de la opinión pública }\end{array} & \begin{array}{c}\text { Lugar de la instancia } \\ \text { ciudadana o } \\ \text { gobernados en la } \\ \text { perspectiva semiótica } \\ \text { teniendo en cuenta la } \\ \text { analogía con el teatro } \\ \text { griego. }\end{array} \\ \text { Gobernantes / } & \text { Gobernantes /Opinión/ } \\ \text { Gobernados } & \text { Gobernados }\end{array}$

Figura 3. Perspectiva sociológica, perspectiva semiótica y la instancia ciudadana.

Sin embargo, Landowski señala, que si las denominaciones que designan un actor colectivo como "ciudadanos", "franceses" son apenas un problema de estilo y pueden leerse como sinónimos, entonces: ¿cómo dar cuenta de un enunciado como el siguiente?:

Durante tres años el jefe de
Estado no tendrá que vérselas
con los electores sino con
la opinión sondeada por
los institutos y expresada
por los periodistas [ ...](
Patrick Jarreau,“ la reunión
de presse du président de la
République", Le Monde, 16
de junio de 1978)

De acuerdo con este ejemplo, para Landowski, existe una diferencia entre el elector y la opinión pública, ambas son presentadas como dos instancias separadas que asumen roles distintos, la primera hace ser a los gobernantes a través de su poder de elección, pero al concluir este ejercicio su accionar queda aspectualmente concluido hasta un nuevo proceso electoral; la segunda, tiene por competencia modal hacer actuar a los gobernantes al ejercer una presión a través de su opinión, la cual es expresada a través de los medios. En 
este caso, su accionar tiene un carácter durativo, al implicar que los gobernantes tendrán que vérsela con la opinión pública durante todo su mandato. Por lo tanto, nos encontramos no ante dos sino ante tres instancias "autónomas" distintas: los gobernantes, la opinión y los gobernados.

\section{Reparto de competencias}

De acuerdo con Landowski, «la clase política que no se relaciona solo ni directamente con el público, sino con los mediadores encargados de "personificarlo". [...] Mediación que se encuentra compartida entre dos figuras principales [...] [en el teatro griego], se sabe, que al lado del coro [se situaba el corifeo], introduciendo una mediación suplementaria entre la escena y las gradas del teatro. De manera análoga, el sistema escenográfico implícito que es hoy la base de la transformación de la vida política en un "espectáculo" implica la colocación, entre los "gobernantes" y los "gobernados", de dos figuras distintas: la "opinión”, por un lado, y sus "portavoces", por otro. (1989 p.31)

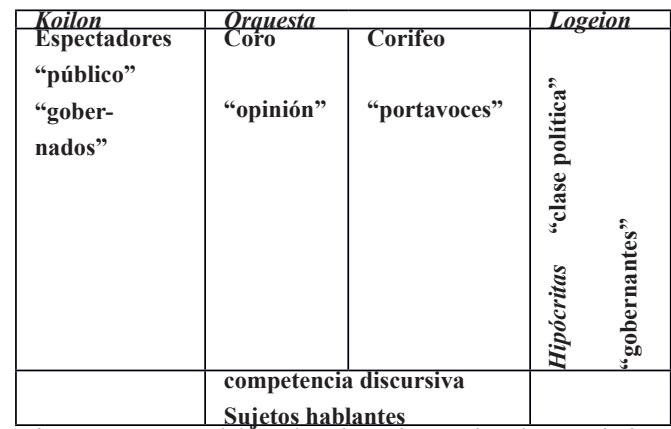

Figura 4. Doble destinación de la opinión pública.

Primero que todo señalemos, que la instancia denominada espectadores, público o gobernados por su condición de ser una totalidad partitiva, i.e., compuesta de voces individuales y desarticuladas no llega nunca a ser un emisor y por tanto se instituye solo como instancia receptora. En el lado opuesto están los gobernantes o protagonista del espectáculo político, y situadas en el centro, las dos instancias que median entre gobernados y gobernantes: la opinión y los portavoces. Según Landowski, la opinión tiene una función persuasiva, en tanto que los portavoces tienen una función interpretativa:

El discurso de la opinión (coro) se analiza como un discurso de persuasión destinado tanto a hacer actuar a la clase política como a hacer asumir al público una cierta visión de su propia identidad. [...] Simétricamente, los discursos de interpretación emitidos por los portavoces (corifeo) están destinados a la vez a hacer conocer a los gobernantes las reacciones del «pueblo» [...] $\mathrm{y}$, a su vez, a hacer comprender al público la significación y las implicaciones de las conductas adoptadas en la escena política (Landowski, 1989 p.p.31-32).

Dicho de este modo, la opinión, como instancia enunciadora, ejerce el rol de destinador manipulador para hacer-hacer a la clase política y que esta actúe en favor de sus demandas, y hacer-ser al público de tal forma que se produzca en él un nuevo estado al asumir la identidad propuesta por la opinión. Concomitantemente, los portavoces, de acuerdo a su interpretación, hacen-saber a los gobernantes los juicios $\mathrm{y}$ valoraciones hechos por el pueblo $\mathrm{y}$, a su vez, hacer interpretar al público la repercusión y/o conveniencia de las actuaciones de la clase política.

Lo anterior le permite a Landowski concluir:

De este conjunto de relaciones se desprenden finalmente dos tipos esenciales de 
intervenciones de la opinión: unas apuntan a la acción de los «héroes», las otras a las convicciones del auditorio. Desde este punto de vista, la opinión no es, como se dice a menudo, «manipulada» por el contrario, es la gran manipuladora. (Landowski. 1989 p.32)

La Opinión pública, doble destinación:

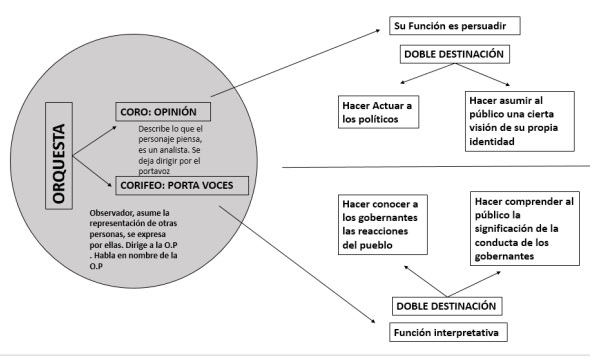

Figura 5. Doble destinación de la opinión pública.

\section{Dos saberes enfrentados: Encuestadores y portavoces}

\section{Para Landowski:}

Es interesante, en primer lugar, destacar hasta qué punto los periodistas y los políticos, en su trabajo de historiadores del presente, se comportan como los fieles adeptos de una fórmula narrativa bastante conocida, la que, en el terreno literario, se conoce como la visión "del interior" (Todorov). A esta fórmula, tradicionalmente fundada en el postulado de la transparencia de los "personajes" para el narrador que los hace entrar en escena, una vez puesta en el contexto de los discursos políticos, se anexa un campo de aplicación que va más allá de la simple psicología de los caracteres individuales, y permite así fundar una especie psicología social basada en el "alma" misma de los actantes colectivos. Dado que la omnisciencia del escritor ante sus propias criaturas "de papel" se encuentra así igualada o incluso sobrepasada por la capacidad de visión en profundidad que todo gran comentador de la vida política moderna debe poseer, no podemos ignorar los "estados del alma de la opinión pública", su manera de reaccionar a los sucesos del momento, sus deseos más profundos: nada de esto podría escapar del dominio de la clarividencia de aquellos cuya profesión es "informarnos" (Landowski. 1989 p. 34).

Landowski, recurre a la estructura ficcional para destacar como los portavoces (periodistas y políticos) hacen entrar en la escena discursiva a la opinión pública como un actante colectivo. Los portavoces, narradores omniscientes en sus relatos, construyen su "personaje de papel" dotado de los sentimientos, saberes y pasiones más recónditos que solo su creador es capaz de vislumbrar y para «atenuar la gratuidad aparente de las certidumbres así establecidas, [...] «al lado del discurso intuitivo y adivinatorio de los portavoces, hay lugar también para el discurso de los encuestadores y de los sondeadores de oficio» (Landowski. 1993 p.35), cuyo manejo de las estadísticas, ha dado lugar a pensar que se está ante un verdadero dispositivo científico que permite conocer lo que realmente piensa la ciudadanía sobre su realidad nacional y, de paso, induce a crear la entelequia de un sistema abiertamente democrático que escucha y se interesa por lo que expresan sus ciudadanos. Sin embargo, no son estos sondeos los 
que sirven para validar el «discurso adivinatorio de los portavoces, surgidos del olfato político y de su intuición psicológica que les permite conocer el alma de los ciudadanos, al contrario, es el sondeo, el que se pone en tela de juicio en función de la concordancia de sus resultados con las certidumbres a priori de los visionarios de la opinión» Landowski. 1993 p. 35). Estos dos tipos de información derivados de dos saberes distintos configuran modalmente a la opinión de diferente manera.

Dice Landowski (1989): las dos principales posiciones que puede tener [la opinión] cuando se trata de entender "como gobierna el mundo":

(1) $[\ldots]$ El narrador podrá utilizarla como instancia de decisión: decir que la opinión gobierna conducirá entonces a afirmar que la acción política de las autoridades depende de la expresión de las voluntades de una opinión - árbitro, que tiene por ley el derecho de dictar a la "clase política" lo que debe hacer (p. 36)

(2) $[\ldots]$ El relato podrá igualmente- si se sitúa en el nivel de la ejecución de los programas políticossubordinar lo que el "Poder" puede hacer a los comportamientos estratégicos del actante colectivo, considerado ésta vez como una potencia susceptible de prestar su concurso a los "gobernantes", o de rechazarlo. (p. 36-37)

En el primer caso, la opinión es construida en el referente enunciado como un sujeto actorializado y es presentada como responsable de la decisión de los gobernantes; el rol actancial que se le asigna es el de un destinador manipulador que asigna deberes a la clase política. En el segundo caso la opinión es presentada como auxiliar o colaborador en la toma de decisiones de los gobernantes.

Para Landowski (1993) en el sondeo, la información obedece a datos cuantitativos y por tanto la opinión se presenta como un «quantum de poder», una totalidad partitiva, compuesta de una multitud de voces desarticuladas, pero con el peso del dato, visto así, el estatus de la opinión es el de la fuerza (p.36) en el sentido de que como cifra adquiere el poder para "obligar [al gobernante] a que asienta a algo, o a que lo haga" (DRAE). Desde este punto de vista, la estructura modal de la opinión es el «poder».

Por otra parte, dice Landowski, el discurso de los portavoces se sitúa en el plano de la descripción y la evaluación cualitativa. Como totalidad no cuantificable, la opinión pública es configurada como un actor que asume el papel de árbitro para intervenir en las elecciones axiológicas, los portavoces son los encargados de hacer saber dicho arbitraje. En este sentido, la estructura modal de la opinión pública es la del «querer» (p.36).

La opinión pública constituye, pues, un simulacro en permanente construcción, en ella convergen puntos de vista tan diversos y heterogéneos como los actores sociales que le dan vida: sectores políticos, medios de comunicación pertenecientes a diversas filiaciones ideológicas, grupos sociales, de allí que sea imposible asignarla a alguien en particular. «Ella se presenta a la vez fragmentada y homogénea, reactiva $\mathrm{y}$ asignada, autónoma y bajo influencia, es decir, bajo forma plural: [no tenemos, pues] una opinión pública sino opiniones públicas». (Charaudeau. 2013 p. 31) 
Para finalizar esta reflexión sobre la forma como se configura discursivamente la opinión pública digamos, entonces, que la opinión es una acción discursiva y como tal debe ser rastreada en el enunciado para establecer quién es el responsable de esa acción, quién la configura, cómo y qué configura en su discurso. El enunciador configura el referente de una determinada manera para el enunciatario, es decir, hace ser la opinión, la hace existir, le da vida en el discurso y concomitantemente la hace saber; este hacer informativo, que conlleva en sí mismo un sesgo orientador de la interpretación, tiene como propósito buscar la adhesión del público, hacer creer la información para que se produzca en el enunciatario un hacer interpretativo quien, a través de un juicio epistémico, decide creer o no creer el referente configurado.

\section{Referencia Bibliográfica.}

Charaudeau, Patrick (2013) La conquête du pouvoir. Opinion, persuasión, valeur. Les discours d'une nouvelle donne politique. L'Harmattan. Paris.

Landowski, Eric (1989) La société. Réfléchie. Seuil. Paris.

López, G. Guillermo. (2001) Comunicación electoral y formación de la opinión pública. Tesis Doctoral. Universidad de Valencia. Recuperado de: http://www. uv.es/=guilopez/documentos/

Real Academia Española. (2014). Opinión. En Diccionario de la lengua española (23. ${ }^{\circ}$ ed.) Recuperado de: http://dle.rae. es/?id=R6gqDaZ

Diccionario Larousse. (2016). Opinión. Recuperado de http://www.larousse.mx/ app/diccionario-frances-espanol-2/

Moliner, M. (1967). Opinión. Diccionario de uso del español.(1 ${ }^{\mathrm{a}}$. ed.). Madrid: Gredos.

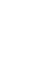

